\title{
TEKA-TEKI MINANGKABAU: DOKUMENTASI DAN KLASIFIKASI
}

\author{
Nahdatul Naumi ${ }^{1 *}$, Yerri Satri Putra ${ }^{2}$, Eka Meigalia $^{3}$ \\ nahdatulnaumi@gmail.com* \\ Fakutas Ilmu Budaya Universitas Andalas 1,2,3
}

\begin{abstract}
ABSTRAK
Tulisan ini merupakan hasil penelitian mengenai teka-teki yang ada di Kabupaten Agam, Sumatera Barat. Pentingnya pewarisan sejak dini berguna untuk mempertahankan bahasa daerah maupun kebudayaan setempat. Tujuannya adalah mendokumentasikan dan mengklasifikasikan jenis dan kategori teka-teki yang ada di Kabupaten Agam.

Penelitian ini menggunakan metode kualitatif dengan pendekatan folklor, dan menggunakan tiga tahap penelitian. Pertama, tahap prapenelitian di tempat, kedua tahap penelitian di tempat yang sesungguhnya dan ketiga, cara pembuatan naskah folklor untuk pengarsipan. Teknik pengumpulan data dilakukandengan studi lapangan, wawancara, pengujian kebenaran data wawancara, dan alat bantuan bagi daya pengamatan.

Dari 80 data yang diperoleh, diklasifikasikan berdasarkan sifat dan terdapat tujuh kategori umum yaitu:1) persamaan dengan makhluk hidup, terdapat tiga belas data 2) persamaan dengan binatang, terdapat enam belas data ditambah satu data yang dipersamakan ke dalam persamaan dengan manusia, 3) persamaan dengan manusia, terdapat delapan belas data, ditambah satu data yang dipersamakan ke dalam persamaan dengan binatang 4) persamaan dengan tanaman, terdapat empat data dan 5) persamaan dengan benda, terdapat tiga puluh satu data.
\end{abstract}

Kata-kata kunci: Teka-Teki, Folklor, Kabupaten Agam, Dokumentasi, Klasifikasi.

\section{MINANGKABAU TRADITIONAL PUZZLES: DOCUMENTATION AND CLASSIFICATION}

\begin{abstract}
This paper is the result of research on a traditional puzzle in Agam Regency, West Sumatra. The importance of inheritance from an early age helps maintain the local language and culture. The aim is to document and classify the types and categories of puzzles in the Agam District.

This study uses a qualitative method with a folklore approach and uses three stages of research. The method in this research is the on-site pre-research stage, the second in-place research stage, and the third, the method of making folklore scripts for archiving. Data collection techniques are carried out by field studies, interviews, testing the correctness of interview data, and observation power tools.

Of the eighty data obtained, they are classified based on characteristics. There are seven general categories, namely: 1) equality with living things, there are thirteen data 2) equations with animals, there are sixteen data plus one data that is equated into equations with humans, 3 ) equations with humans, there are eighteen data, plus one data that equates to equations with animals 4) equations with plants, there are four data and 5) equations with objects, there are thirty-one data.
\end{abstract}

Keywords: Puzzle, Folklore, Agam Regency, Documentation, Minangkabau. .

Jurnal Elektronik WACANA ETNIK - Vol 8 No 2, 2019, (166 - 181) p ISSN 2089-8746, e ISSN 2302-7142

Submit: Agustus 2019. Diterima: September 2019. Publikasi: Oktober 2019. 


\section{PENGANTAR}

Pertanyaan tradisional atau teka-teki merupakan salah satu bentuk folklor lisan yang ada di nusantara. Tekateki dapat ditemukan dalam kehidupan masyarakat Minangkabau, karena orang Minangkabau sejak dulu hidup dalam tradisi kelisanan, tapi tidak semua orang dapat menyampaikan teka-teki, hanya orang-orang tertentu yang pandai dalam mengolah kata-kata untuk bermain teka-teki. Teka-teki bisa dibuat di mana saja dan kapan saja atau boleh dikatakan tidak mengenal waktu. Peranan penting dalam teka-teki ini adalah sebagai hiburan dan pengisi waktu luang, juga bisamengasah otak untuk menguji kepandaian seseorang.

Selain itu, teka-teki merupakan pencerminan sikap dan pandangan hidup suatu kelompok masyarakat. Sesuai dengan hasil pengamatan, perkembangan pertanyaan tradisional seperti teka-teki di kalangan masyarakat sudah mulai berkurang dan dikhawatirkan suatu saat akan hilang. Jika keberadaan ini dibiarkan berlanjut, maka konsekuensinya generasi muda yang ada di Kabupaten Agam tidak dapat mengetahui kekayaan budaya mereka sendiri. Sastra Daerah yang berupa teka-teki sangat menarik untuk diteliti, karena nilai-nilai yang terkandung di dalamnya dapat memperlihatkan ciri khas pemikiran seseorang.

Alasan peneliti memilih penelitian di Kabupaten Agam supaya teka-teki lebih dikenal oleh masyarakat umum, khususnya bagi generasi muda sekarang yang sudah banyak terpengaruh perkembangan zaman, saat ini tidak banyak orang yang dapat atau mampu mengolah kata untuk memainkan teka-teki, hanya orang-orang tertentu saja, seperti kaum tua terdahulunya dan orang yang biasa duduk di lapau. Karena keterbatasan orang yang bisa bermain teka-teki inilah peneliti ingin menggali lebih dalam folklor lisan yang berbentuk teka-teki yang ada di Kabupaten Agam, selama ini proses pewarisannya hanya secara lisan saja, dikhawatirkan sistempewarisannya tidak sampai ke generasi muda sekarang. Maka, perlu adanya usaha peneliti untuk mendokumentasikan pertanyaan tradisional dan dituangkan dalam bentuk tulisan agar warisan budaya lisan Minangkabau bisa terjaga kelestariannya. Artikel ini merupakan deskripsi hasil dokumentasi dan klasifikasi bentuk teka-teki Minangkabau yang ada di Kabupaten Agam Sumatera Barat.

\section{KERANGKA TEORI DAN METODE}

Pada penelitian ini peneliti memfokuskan pada folklor lisan, khususnya pertanyaan tradisional atau teka-teki yang ada di Kabupaten Agam. Taylor (dalam Danandjaja, 1991:36) mengelompokkan pertanyaan tradisional ke dalam tujuh kategori. Pengelompokkan ini berdasarkan sifat hal yang digambarkan di dalam pertanyaan tradisional. Ketujuh kategori tersebut yaitu, a) persamaan dengan makhlukhidup; b) persamaan dengan binatang; c) persamaan dengan beberapa binatang; d) persamaan dengan manusia; e) persamaan dengan beberapa orang; f) persamaandengan tanaman; g) persamaan dengan benda. Seperti bentuk-bentuk folklor lainnya, pertanyaan tradisional juga memiliki fungsi, Dundes (dalam Danandjaja, 1991:45) menyebut ada enam fungsi pertanyaan tradisional dalam masyarakat, yaitu (1) untuk menguji kepandaian seseorang, (2) untuk meramal, (3) sebagai bagian dari upacara perkawinan, (4) untuk mengisi waktupada saat begadang menjaga jenazah yang belum dimakamkan, (5) untuk melebihi orang lain.

Jurnal Elektronik WACANA ETNIK - Vol 8 No 2, 2019, (166 - 181) p ISSN 2089-8746, e ISSN 2302-7142 
Dalam penelitian ini metode yang digunakan adalah metode kualitatif dengan pendekatan folklor. Menurut Danandjaja (2002:193). Penelitian macam pengumpulandengan tujuan pengarsipan atau pendokumentasian ini bersifat penelitian di tempat (field work). Ada tiga tahap yang dilalui dalam penelitian ini. Tiga tahap itu pertama, tahap prapenelitian di tempat, kedua tahap penelitian di tempat yang sesugguhnya, dan ketiga cara pembuatan naskah folklor bagi pengarsipan.

\section{HASIL DAN PEMBAHASAN}

Penelitian ini bertujuan untuk melakukan pengarsipan teka-teki yang ada di Kabupaten Agam, sekaligus mengklasifikasikan berdasarkan sifat yang digambarkan di dalam teka-teki yang diperoleh. Data tersebut dikumpulkan melalui penelitian lapangan, observasi, menyangkut tempat penelitian dan objek yang ingin diteliti, lalu menentukan informan yang diwawancarai. Informannya meliputi salah satu dari pemuka masyarakat diantaranya tokoh masyrakat, niniak mamak, alim ulama, cadiak pandai, dan masyarakat setempat yang dapat memberikan keterangan yang diperlukan untuk penelitian teka- teki Minangkabau ini. Setelah menentukan para informan, peneliti mulai melakukan wawancara dengan informan. Wawancara dilakukan melalui komunikasi secara lisan dengan narasumber.

\section{PERSAMAAN DENGAN MAKHLUK HIDUP}

Teka-teki persamaan dengan makhluk hidup adalah teka-teki yang unsurpelukisan pertanyaannya memiliki persamaan dengan makhluk, sebagai berikut.

Inyo manuruik, tiok dikajanyo lari, ea tu? Bayang-bayang

Dia mengikut, setiap dikejar dia lari, apa itu? Bayang-bayang

Pada pertanyaan di atas, kata manuruik(mengikut) dan lari merupakan kata sifat yang dimiliki oleh mahkluk hidup, bisa ditujukan kepada manusia maupun binatang. Jadi teka-teki di atas dipersamakan ke dalam persamaan dengan makhlukhidup.

Ka bawah lambek ka ateh capek, apo koyo? salemo

Ke bawah lambat, ke atas cepat, apa itu? ingus

Pada pertanyaan di atas, kata lambek (lambat) dan capek (cepat) merupakan kata sifat yang dimiliki oleh mahkluk hidup,bisa ditujukan kepada manusia maupun binatang yang mempunyai kecepatan dalam bergerak. Jadi teka-teki diatas dipersamakan ke dalam persamaan dengan mahkluk hidup.

Ka pai madok ka pulang, ka pulang madok ka pai, ea tu?Urang mambaok parian Mau pergi melihat ke arah pulang, mau pulang melihat ka arah pergi, apa itu?orang membawa air

Pada pertanyaan di atas, kata madok (melihat) merupakan kata sifat yangdimiliki oleh mahkluk hidup yaitu mata. Mata merupakan organ penglihatan yang dimiliki manusia maupun binatang.Jadi teka-teki di atas dipersamakan ke dalampersamaan dengan mahkluk hidup.

Kaki tigo mangko bajalan, mato ampek mangko maliek, aya tu? Urang tuo Kaki tiga bisa berjalan, mata empat bisa melihat, apa itu? orang tua 
Pada pertanyaan di atas, kata bajalan (berjalan) dan maliek (melihat) merupakan sifat dari mahkluk hidup, bisa ditujukan kepada manusia maupun binatang. Jadi teka-teki di atas dipersamakan ke dalam persamaan dengan makhluk hidup.

Bagolek-golek mancari nyao, dapek nyao badan tabuang, aya tu? Ayam batalua

Berguling-guling mencari nyawa, nyawa dapat badan terbuang, apa itu? Ayam bertelur

Pada pertanyaan di atas, kata bagolek-golek (berguling-guling) dan nyao (nyawa) merupakan sifat dari mahkhluk hidup, bisa ditujukan kepada manusia maupun binatang. Jadi teka-teki di atas di persamakan ke dalam persamaan denganmahkluk hidup.

Luko ndak taraso, lah badarah sajo mangko ka tau, a tu? acek Luka tidak terasa, sudah berdarah saja ketahuan, apa itu? pacet

Pada pertanyaan di atas, kata taraso (terasa) dan badarah (berdarah) merupakan sifat dari mahkluk hidup yang bisa mengeluarkan darah ketika terkena benda tajam. Bisa ditujukan kepada manusia maupun binatang. Jadi teka-teki di atas dipersamakan ke dalam persamaan dengan mahkluk hidup.

Katokan buah ndak batangkai, katokan buruang tak banyao, sabulan maiktarampai, badan kuduang nyao tibo, a tu? Ayam maram

Dikatakan buah tidak bertangkai, dikatakan burung tidak bernyawa, sebulan mayat tergeletak, badan belah nyawa datang, apa itu? ayam mengeram

Pada pertanyaan di atas, kata batangkai (bertangkai), buruang (burung) maik (mayat) dan badan, merupakan sifat yang dimiliki oleh makhluk hidup, padakalimat pertama ditujukan kepada tanaman, sedangkan kata burung merupakan binatang, lalu mayat adalah manusia. ketiganya merupakan mahkluk hidup yang bisa bernafas dan bergerak. Jadi teka-teki di atas dipersamakan ke dalam persamaan dengan mahkluk hidup.

Makannyo diparuik, taciriknyo ka pungguang, ea tu ? katam kayu

Makannya diperut, buang airnya ke perut, apa itu? mesin pengetam kayu

Pada pertanyaan di atas, kata makan dan tacirik (buang kotoran) merupakan sifat dari mahkluk hidup, namun tidak cocok di tujukan pada manusia. Jadi teka- teki di atas dipersamakan ke dalam persamaan dengan mahkluk hidup.

Keteknyo jadi kawan, gadangnyo manjadi lawan, apo koyo? api

Kecil jadi teman, besar menjadi musuh, apa itu? api

Pada pertanyaan di atas kata kawan dan lawan merupakan sifat dari mahkluk hidup yang saling berinteraksi satu sama lain. Jadi teka-teki di atas dipersamakan ke dalam persamaan dengan mahkluk hidup.

Pantang tasinguang, indak dibaok manuruik juo, a tu? Daun puluik-puluik

Pantang tersentuh, tidak dibawa dia ikut juga, apa itu? daun pulut-pulut

Pada pertanyaan di atas kata tasingguang(tersentuh) dan manuruik (mengikut) merupakan sifat dari mahkluk hidup yang memiliki organ tubuh untuk begerak seperti kaki. Jadi teka-teki di atas dipersamakan ke dalam persamaandengan makhluk hidup.

Dilao nyo manggarik, ndak disapo nyo diam, a tu? sikajuik

Disenggol dia bergerak, tidak disapa diam saja, apa itu? sikejut/putri malu

Jurnal Elektronik WACANA ETNIK - Vol 8 No 2, 2019, (166 - 181) p ISSN 2089-8746, e ISSN 2302-7142 
Pada pertanyaan di atas, kata manggarik (bergerak) dan disapo (disapa) merupakan sifat yang dimiliki oleh mahkluk hidup yang bisa bergerak dan mendengar. Bisa ditujukan kepada manusia maupun binatang. Jadi teka-teki di atasdipersamakan ke dalam persamaan dengan mahkluk hidup.

Bamato tigo, mancaliak ciek, ea tu? galuak

Matanya tiga, melihat satu, apa itu? tempurung

Pada pertanyaan di atas, kata mancaliak (melihat) merupakan sifat yang hanyadimiliki oleh mahkluk hidup saja. Jadi teka-teki di atas dipersamakan ke dalam persamaan dengan mahkluk hidup.

Nan maliek indak bakapalo, nan lari indak baikua, nan mangaja indak bakaki,apotu? ula

Yang melihat tidak berkepala, yang lari tidak berekor, yang mengejar tidak berkaki, apa itu? ular

Pada pertanyaan di atas,kata maliek (melihat) bakapalo (berkepala), baikua (berekor) dan bakaki (berkaki) merupakan sifat yang dimikili oleh mahkluk hidup, bisa ditujukan kepada manusia maupun binatang. Jadi teka-teki ini dipersamakan ke dalam persamaan dengan mahkluk hidup.

\section{PERSAMAAN DENGAN BINATANG}

Teka-teki persamaan dengan binatang adalah unsur pelukisan pertanyaanmemiliki persamaan dengan binatang sebagai berikut.

Dikakok nyo jinak, dicaliak nyo lari, apo koyo? talingo

Dipegang dia jinak, dilihat dia lari, apa itu? telinga

Pada pertanyaan di atas, kata jinak merupakan kata yang paling cocok ditujukan kepada binatang, pada hakikatnya jinak adalah sifat naluriah binatang kepada tuannya yang telah memeliharanya. Jadi teka-teki di atas dipersamakan ke dalam persamaan dengan binatang.

Talua-talua ea nan batangkai, a tu? Talua kutu

Telur-telur apa yang bertangkai, apa itu? telur kutu

Pada pertanyaan di atas, kata talua (telur) merupakan sifat dari binatang, bertelur adalah cara binatang untuk mengeluarkan keturunannya. Meskipun ada beberapa binatang yang bisa melahirkan, tetapi binatang sejenis unggas menghasilkan keturunan dengan cara bertelur. Jadi teka-teki di atas dipersamakan ke dalam persamaan dengan binatang.

Kalau bajalan kakinyo duo, kalau baranti kakinyo sapuluah, a tu? Tukang sate

Kalau berjalan kakinya dua, kalau berhenti kakinya sepuluh, apa itu? tukang sate

Pada pertanyaan di atas, kata kakinyo duo (kakinya dua) merupakan persamaan dengan manusia, sedangkan kakinyo sapuluah (kakinya sepuluh) merupakan persamaan dengan binatang. Jadi teka-teki di atas dipersamakan ke dalam persamaan dengan binatang. Karena yang memiliki kaki lebih dari dua hanyalah binatang.

Gadang kapalo pado badan, a tu? sipatuang

Besar kepala dari pada badan, apa itu? capung

Pada pertanyaan di atas, besar kepala dari badan merupakan bentuk tubuh yang dimiliki binatang jenis serangga, contohnya capung yang memiliki bentuk tubuh tersebut, Jadi teka-teki di atas dipersamakan ke dalam persamaan dengan binatang.

Jurnal Elektronik WACANA ETNIK - Vol 8 No 2, 2019, (166 - 181) p ISSN 2089-8746, e ISSN 2302-7142 
Siang lalok, malam malewa, a tu? lampang

Siang tidur, malam berkeliaran, apa itu? kelelawar

Pada pertanyaan di atas, siang tidur malam berkeliaran merupakan sifat binatang yang dimilliki kelelawar, binatang yang aktif dimalam hari iniberkeliaran pada malam hari bertujuan untuk mencari makan, karena pada siang hari penglihatan kelelawar sangat buruk sekali. Jadi teka-teki di atas dipersamakanke dalam persamaan dengan binatang.

Dulu bulu mambuek gata, kini warna marancak $i$, a tu? Ramo-ramo

Dulu bulu yang membuat gatal, sekarang warna yang membuat bagus, apa itu? kupu-kupu

Pada pertanyaan di atas, kata bulu membuat gatal dan warna membuat bagus merupakan sifat yang dimiliki oleh binatang yaitu kupu-kupu, kupu-kupu adalah hewan yang bermetamofosis dari ulat menjadi kupu-kupu, ia memiliki bulu yang bisa membuat kulit manusia merasa gatal. Lalu mempunyai warna yang sangat menarik. Jadi tekateki di atas dipersamakan ke dalam persamaan dengan binatang.

Masuak mahereang, kalua mahereang lo, a tu? Buah baju

Masuk miring, keluar miring, apa itu? kancing baju

Pada pertanyaan di atas, masuak mahereang (masuk miring), kalua mahereang (keluar miring) merupakan sifat yang dimiliki oleh binatang yaitu kepiting kalau berjalan miring kekiri dan kekanan karena memiliki kaki dibagian kiri dan kanan. Jadi teka-teki di atas dipersamakan ke dalam persamaan dengan binatang.

Induaknyo manilantang sajo, anaknyo maonjak-onjak, a tu? Batu lado

Ibunya berbaring saja, anaknya melompat-lompat, apa itu? ulekkan cabe

Pada pertanyaan di atas, kata induaknya (induknya) merupakan kata yang cocok ditujukan kepada binatang, induk merupakan sebutan bagi binatang betina yang mempunyai anak. Jadi teka-teki di atas dipersamakan ke dalam persamaan dengan binatang.

Basorak induak nyo, balari anaknyo, a tu? badia

Berteriak ibunya, berlari anaknya, apa itu? senapan angin

Pada pertanyaan di atas, kata basorak induaknya (berteriak induknya), balari anaknyo (berlari anaknya) merupakan kalimat yang cocok ditujukan kepada binatang yang sedang memanggil anaknya, induk merupakan sebutan bagi binatang betina yang mempunyai anak. Jadi teka-teki di atas dipersamakan ke dalam persamaan dengan binatang.

Anak, anak ea nan tak dilahiakan? Anak janjang

Anak-anak apa yang tidak dilahirkan? Anak tangga

Pada pertanyaan di atas, anak ea nan tak dilahiakan (anak apa yang tidak dilahirkan) merupakan kata yang cocok ditujukan kepada binatang, karena sebagian binatang terlahir melalui proses telur yang dierami oleh induknya, berbeda dengan anak manusia yang keluar melalui proses melahirkan. Jadi teka- teki diatas dipersamakan ke dalam persamaan dengan binatang.

Disabuik sakali ampek kakinyo, disabuik duo kali balah paruiknyo, apo tu?Kuciang-kiciang Disebut sekali empat kakinya, disebut dua kali belah perutnya, apa itu? kucing-kucing 
Pada pertanyaan di atas, ampek kakinyo (empat kakinya) merupakan kata yangditujukan kepada binatang, karena binatang pada umumnya mempunyai empat kaki bahkan lebih. Jadi teka-teki di atas dipersamakan ke dalam persamaan dengan binatang.

Induaknyo duduak sajo, anaknyo maharau-harau, aya tu? Pariuak jo sanduaknyo

Ibunya duduk saja, anaknya berisik sekali, apa itu? panci dan sendoknya

Pada pertanyaan di atas, kata induaknya (induknya) merupakan kata yang cocok ditujukan kepada binatang, induk merupakan sebutan bagi binatang betina yang mempunyai anak. Jadi teka-teki di atas dipersamakan ke dalam persamaan dengan binatang.

Batalaua di ateh awang-awang, manateh ditalapak tangan, ea tu? Buah manggih

Bertelur di awang-awang, menetas ditelapak tangan, apa itu? buah manggis

Pada pertanyaan di atas, kata batalua (bertelur) dan manateh (menetas) merupakan kata yang ditujukan kepada binatang sejenis unggas, yang berkembangbiak melalui proses bertelur, lalu mengeram sampai terlur-telur itu menetas. Jadi teka-teki di atas dipersamakan ke dalam persamaan dengan binatang.

Basisiak bukannyo nago, bagonjong bukannyo rumah, bapayuang bukannyo rajo,co takok? naneh Bersisik bukannyo naga, bergonjong bukannya rumah, berpayung bukannya raja, coba tebak? buah nanas

Pada pertanyaan di atas, kata nago (naga) merupakan persamaan dengan binatang, sedangkan rumah merupakan persamaan dengan benda, dan rajo (raja) merupakan persamaan dengan manusia, namun jawabannya adalah naneh (nanas) persamaan dengan tanaman. Jadi teka-teki di atas bisa dipersamakan kedalam empat jenis tersebut berdasarkan sifatnya masing-masing.

Iduik talunta-lunta, dima inggok mambaleh guno, a tu? Batang pelo

Hidup terlunta-lunta, dimana hinggap membalas guna, apa itu? ubi

Pada pertanyaan di atas, kata inggok (hinggap) merupakan kata yang hanya diperuntukkan pada binatang yang mempunyai sayap untuk terbang. Jadi teka-teki di atas dipersamakan ke dalam persamaan dengan binatang.

Kapalonyo runciang, ikuanyo runciang, apo tu? sabuik Kepalanya runcing, ekornya runcing, apa itu? kulit kelapa

Pada pertanyaan di atas, kata kapalonyo runciang, ikuanyorunciang (kepalanya runcing, ekornya runcing) seperti mendeskripsikan bentuk binatang tapir yang memiliki bentuk mulut yang runcing kedepan berfungsi untuk menghisap makanan seperti semut yang ada di sarangnya dan memiliki ekor yang runcing. Jadi teka-teki di atas dipersamakan ke dalam persamaan dengan binatang.

\section{PERSAMAAN DENGAN MANUSIA}

Teka-teki persamaan dengan manusia adalah unsur pelukisan pertanyaan memiliki persamaan dengan manusia. Hal yang dilukiskan berhubungan dengan pekerjaan, kedudukan,dan sifat-sifatnya sebagai berikut.

Lupo tabao, takana tingga, ea tu? Lacah dikaki

Lupa dia terbawa, kalau ingat dia tinggal, apa itu? kotoran dikaki

Pada pertanyaan di atas, lupo tabao takana tingga (lupa terbawa, ingat dia tinggal) merupakan sifat manusia yang bersifat khilaf. Manusia merupakan mahkluk ciptaan tuhan yang paling istimewa diberi akal fikiran. Lupa dan

Jurnal Elektronik WACANA ETNIK - Vol 8 No 2, 2019, (166 - 181) p ISSN 2089-8746, e ISSN 2302-7142 
ingat merupakan sifat yang alami terjadi pada manusia. Jadi teka-teki di atasdipersamakan ke dalam persamaan dengan manusia.

Si hitam mandi ka lubuak, hitam jajak nyo jadi kato-kato, aya tu? Kalam saga

Si hitam mandi ke sungai, hitam jejaknya jadi kata-kata, apa itu? gelap gulita

Pada pertanyaan di atas, kato-kato (kata-kata) merupakan sifat yang hanya dimiliki dan dimengerti oleh manusia melalui alat indranya yaitu mulut, kata-kata dalam pertanyaan tersebut maksudnya seseorang yang sedang berbicara pada dirinya sendiri tidak memerlukan lawan bicara. Jadi teka-teki di atas dipersamakanke dalam persamaan dengan manusia.

Kalau bajalan kakinyo duo, kalau baranti kakinyo sapuluah, a tu? Tukang sate

Kalau berjalan kakinya dua, kalau berhenti kakinya sepuluh, apa itu? tukang sate

Pada pertanyaan di atas, kata kakinyo duo (kakinya dua) merupakan persamaan dengan manusia, sedangkan kakinyo sapuluah (kakinya sepuluh) merupakan persamaan dengan binatang. Jadi teka-teki di atas dipersamakan ke dalam persamaan dengan manusia. (sama dengan 3.3.2:3)

Urang sarumah ndak bakatahuan, ea tu? talingo

Orang satu rumah tidak tahu sama sekali, apa itu? telinga

Pada pertanyaan di atas, urang sarumah (orang serumah) merupakan sebutan tempat tinggal bagi manusia dan di perjelas dengan kata orang di awal kalimat, bedanya dengan binatang adalah rumah bagi binatang disebut dengan sarang. Jadi teka-teki di atas dipersamakan ke dalam persamaan dengan manusia.

Diarak bukannyo marapulai, dipayuangan bukannyo rajo, ditanam bukannyotinaman, apo kok yo? maik

Diiring bukannya pengantin, dipayungi bukannya raja, ditanam bukannya tanaman, apa itu? mayat

Pada pertanyaan di atas, kata marapulai (pengantin laki-laki) merupakan sebutan bagi manusia yang sedang mengadakan pesta pernikahan, rajo (raja) juga merupakan kata yang ditujukan kepada laki-laki yang memiliki kekuasaan. Jadi teka-teki di atas dipersamakan ke dalam persamaan dengan manusia.

Agak-agak nan diateh, ka ditimpo nan dibawah, aya tu? Urang makan Hati-hati yang di atas, kena timpa yang dibawah, apa itu? orang makan

Pada pertanyaan di atas, agak-agak (hati-hati) merupakan sifat yang dimiliki oleh manusia sebagai mahkluk hidup yang berakal sehat. Jadi teka-teki di atas dipersamakan ke dalam persamaan dengan manusia.

Malam jadi rajo, siang jadi budak, a tu?lampu togok

Malam jadi raja, siang jadi budak, apa itu? lampu minyak

Pada pertanyaan di atas, kata rajo (raja) dan budak di peruntukkan kepada orang yang memiliki kekuasaan tinggi dan rendah. Jadi teka-teki di atas di persamakan ke dalam persamaan dengan manusia.

Amak nyo maunyi rumah, anaknyo malala sajo, a tu? karakatah

Ibunya hanya di rumah, anaknya bermain saja, apa itu? gembok rumah 
Pada pertanyaan di atas, kata amaknyo (ibunya) dan anaknyo (anaknya) merupakan kata panggilan untuk orang tua kepada anakknya maupun seorang anakkepada ibunya. Jadi teka-teki di atas dipersamakan ke dalam persamaan dengan manusia.

Siangnyo manari-nari, malamnyo manapi sajo, a tu? Sapu

Siangnya menari-nari, malamnya menepi saja, apo tu? Sapu

Pada pertanyaan di atas, kata manari-nari (menari-nari) merupakan sifat yang dimiliki oleh manusia melibatkan anggota tubuh seperti tangan, kaki dan pinggul untuk bergerak mengikuti gerakan tersebut serta diiringi suara musik. Jadi teka- teki di atas dipersamakan ke dalam persamaan dengan manusia.

Kaki bagoyang-goyang, tangan manari-nari, a tu? Masin jaik

Kaki bergoyang-goyang, tangan menari-nari, apa itu? mesih jahit

Pada pertanyaan di atas, kaki bagoyang-goyang,tangan manari-nari (kakibergoyang-goyang, tangan menarinari) merupakan gerakan yang di hasilkan oleh organ tubuh manusia untuk melakukan aktifitas yang mengharus kan bagian kaki dan tangan untuk bergerak. Jadi teka-teki di atas dipersamakan ke dalam persamaan dengan manusia.

Apaknyo maratuang, amaknyo sibuk manyasah, anaknyo mangeak sajo, apo tu?Kureta api Bapaknya merokok, ibunya sibuk mencuci, anaknya menangis saja, apa itu? Kereta api

Pada pertanyaan di atas, Apaknyo maratuang (bapaknya merokok) amaknyo sibuk manyasah (ibunya sibuk mencuci) anaknyo mangeak (anaknya menangis), merupakan sifat dari manusia, merokok hanya dapat dilakukan oleh manusia khususnya pada laki-laki, sedangkan kegiatan mencuci pakaian ataupun benda hanya bisa dilakukan oleh manusia saja, dan kata mangeak atau menangis merupakan sifat dari anak bayi yang bermasud memberi tahu ibunya kalau ia dalam keadaan tidak nyaman. Jadi teka-teki di atas dipersamakan ke dalam persamaan dengan manusia.

Basisiak bukannyo nago, bagonjong bukannyo rumah, bapayuang bukannyo rajo, co takok? naneh Bersisik bukannyo naga, bergonjong bukannya rumah, berpayung bukannya raja, coba tebak? buah nanas

Pada pertanyaan di atas, kata nago (naga) merupakan persamaan denganbinatang, sedangkan rumah merupakan persamaan dengan benda, dan rajo (raja) merupakan persamaan dengan manusia, namun jawabannya adalah naneh (nanas) persamaan dengan tanaman. Jadi teka-teki di atas bisa dipersamakan kedalamempat jenis tersebut berdasarkan sifatnya masing-masing.

Kateh-kateh nampak urang tuo mati tagantuang, aya tu? Daun karisiak

Ke atas- ke atas kelihatan orang tua mati tergantung, apa itu? daun pisang yang sudah tua

Pada pertanyaan di atas, urang tuo (orang tua) merupakan sebutan bagi manusia yang sudah berumur 50 tahun ke bawah. Sebutan itu hanya di peruntukkan bagi manusia saja. Jadi teka- teki di atas dipersamakan ke dalam persamaan dengan manusia.

Kateh-kateh basuo urang mati basorak, aya tu? Kalarai jatuah

Ke atas-ketas kelihatan orang mati berteriak, apa itu? daun kelapa tua jatuh

Pada pertanyaan di atas,kata urang mati (orang meninggal) merupakan kata yang diperuntukkan kepada manusia yang sudah tutup usia, namun jawaban dari teka-teki ini persamaan dengan tanaman. Jadi teka-teki di atas dapat dipersamakan ke dalam persamaan dengan manusia.

Jurnal Elektronik WACANA ETNIK - Vol 8 No 2, 2019, (166 - 181) p ISSN 2089-8746, e ISSN 2302-7142 
Bajalan-bajalan nampak darah satitiak, apo tu? sago

Berjalan-jalan tampak darah setitik, apa itu? buah sago

Pada pertanyaan di atas, bajalan-jalan nampak darah satitiak (berjalan-jalan tampak darah setitik) merupakan sifat manusia sedang beraktivitas yang tidak sengaja meliat darah dengan indera penglihatan yaitu mata secara tidak sengaja. Jadi teka-teki di atas dipersamakan ke dalam persamaan dengan manusia.

Dulu tagak barami-rami, kini tabantang urang duduak $i$, a tu? Lapiak pandan

Dulu berdiri bersama-sama, sekarang terbentang orang dudukkan, apa itu? tikarpandan

Pada pertanyaan di atas, kata tagak (berdiri) dan duduak (duduk) merupakan sifat dari manusia yang sedang beraktifitas di luar ruangan akan mebutuhkanwaktu yang lama untuk berdiri dan jika sudah merasa lelah ia akan duduk untuk beristirahat sejenak. Jadi teka-teki di atas dipersamakan ke dalam persamaan dengan manusia.

Urang kaliang mandi darah, co takok? palo

Orang hitam mandi darah, coba tebak? buah pala

Pada pertanyaan di atas, kata urang kaliang mandi darah (orang keling mandi darah) bisa saja diumpamakan seperti orang yang berkulit gelap sedang mengalamikecelakaan mengakibatkan badannya berlumuran darah. Jadi tekateki di atas dipersamakan ke dalam persamaan dengan manusia.

Urang baduo badunsanak, ganti dahulu mandahului, aya tu? Kaki urang

Orang berdua bersaudara, ganti dahulu mendahului, apa itu? kaki orang

Pada pertanyaan di atas, kata badunsanak (bersaudara) merupakan kata yang berlaku pada manusia, yang saling menghormati hubungan persaudaraan, berbeda dengan binatang, walaupun ia bersaudara, tapi mereka bisa saja bertindak sebagai pasangan lawan jenis. Jadi teka-teki di atas dipersamakan ke dalam persamaan dengan manusia.

\section{PERSAMAAN DENGAN TANAMAN}

Teka-teki persamaan dengan tanaman adalah teka-teki yang unsur pelukisanpertanyaannya memiliki persamaan dengan tanaman, sebagai berikut.

Ureknyo diateh, pucuaknyo dibawah, ea tu? jangguik

Uratnya diatas, pucuknya dibawah, apa itu? jenggot

Pada pertanyaan di atas, kata ureknyo (uratnya) dan pucuaknyo (pucuknya) merupakan sifat dari tanaman yang tumbuh melalui urat, apabila sudah besar akan mempunyai pucuk dengan ketinggian kurang lebih satu meter. Tumbuhan menjalar atau menemel pada benda lain ada yang memiliki posisi urat di atas dan pucuknya di menggantung ke bawah. Jadi teka-teki di atas dipersamakan ke dalampersamaan dengan tanaman.

Nan surang kateh, nan surang kabawah, lah manyisiah padi jo bareh a tu? Lasuang panumbuak padi

Satu ke atas, satu lagi ke bawah, tersisih padi dengan beras, apa itu? lesungpenumbuk padi

Pada pertanyaan di atas, kata padi jo atah (padi dengan atah) merupakan makanan pokok bagi manusia yang di tanam melalui proses yang panjang sebelummenjadi nasi. Padi merupakan bentuk sebelum menjadi beras, sementara atahadalah sisa pembersihan yang dibuang sebelum dimasak menjadi nasi. Jadi teka- teki di atas dipersamakan ke dalam persamaan dengan tanaman.

Buah-buah a nan paliang gadang, co takok? Buah rumah

Jurnal Elektronik WACANA ETNIK - Vol 8 No 2, 2019, (166 - 181) p ISSN 2089-8746, e ISSN 2302-7142 
Buah-buah apa yang paling besar, coba tebak? Buah rumah

Pada pertanyaan di atas, kata buah yang paling besar mengacu kepada bentuk dari buah yang terus tumbuh sesuai usia kematangannya, misalnya buah nagka, durian, dan lainnya, yang memiliki ukuran besar. Jadi teka-teki di atasdipersamakan ke dalam persamaan dengan tanaman.

Batang-batang apo nan paliang gadang, apo tu? Batang aia

Batang-batang apa yang paling besar, apa itu? batang air, sungai

Pada pertanyaan di atas, kata batang merujuk kepada tanaman pohon yang berukuran besar, seperti pohon beringin, pohon jati dan lainnya yang berukurang besar dan tinggi. Jadi teka-teki di atas dipersamakan ke dalam persamaan dengan tanaman.

\section{PERSAMAAN DENGAN BENDA}

Teka-teki persamaan dengan benda adalah teka-teki yang unsur pelukisan pertanyaannya memiliki persamaan dengan benda, sebagai berikut.

Kalau laloknyo tagak, kalau tagaknyo lalok, apo koyo? Ampu kaki

Kalau tidur dia berdiri, kalau berdiri dia tidur, apa itu? jari kaki

Pada pertanyaan di atas, kalimat kalau tidur dia berdiri, kalau berdiri dia tidur bisa di perumpamakan seperti benda cangkul yang mempunyai tangkai dan besinya yang lebar, saat posisi tangkai di tidurkan besi pada cangkul akan berdiri, begitu jga sebaliknya ketika tangkai cangkul berdiri, besi pada cangkul akan dalamposisi tidur. Jadi tekateki di atas dipersamakan ke dalam persamaan dengan benda.

Lantai ditembak, iduang nan kanai, co takok? kantuik

Lantai ditembak, hidung yang kena, coba tebak? Kentut

Pada pertanyaan di atas, kata ditembak dan hidung merupakan benda mati yang biasa digunakan manusia untuk menembak sasaran dan untuk bernafas. Jadi teka-teki di atas dipersamakan ke dalam persamaan dengan benda.

Saluang nan di ambuih, mato nan kalimpanan, a tu? Urang maiduikkan api tungku

Salung yang di tiup, mata yang kelilipan, apa itu? orang menghidupkan api di tungku

Pada pertanyaan di atas, saluang (salung) merupakan benda mati yang digunakan dengan cara ditiup. Jadi teka-teki di atas dipersamakan ke dalampersamaan dengan benda.

Di bukak sagadang alam, ditutuik sagadang kuku, co takok? mato

Dibuka sebesar alam, ditutup sebesar kuku, coba tebak? Mata

Pada pertanyaan di atas, kuku merupakan benda mati yang ada pada manusia, ketika kuku sudah panjang, kuku akan dipotong agar terlihat rapi dan bersih. Jadi teka-teki di atas dipersamakan ke dalam persamaan dengan benda.

Dipaguik di onyokkannyo, dipaguik di onyokkannyo, a tu? Urang mamanjek karambia

Dipeluk ditekannya, dipeluk ditekannya, apa itu? orang memanjat kelapa

Pada pertanyaan di atas, "dipeluk ditekannya" merupakan kalimat yang mengarah kepada sesuatu benda mati yang sedang dipeluk sebagai media untuk mencapai sesuatu, seperti tangga atau tiang. Jadi teka-teki di atas dipersamakan kedalam persamaan dengan benda.

Jurnal Elektronik WACANA ETNIK - Vol 8 No 2, 2019, (166 - 181) p ISSN 2089-8746, e ISSN 2302-7142 
Ujuangnyo bakarek, pangkanyo babulu, manyucuakkannyo manyonggeng, apokoyo? Urang batanam banyiah

Ujungnya dipotong,akarnya berbulu, memasukkannya sambil menungging, apaitu? orang sedang menanam benih padi

Pada pertanyaan di atas, kata bakarek (dipotong), babulu (berbulu) dan manyucuakkannyo (memasukkannya) merupakan kata yang merujuk pada suatu benda tajam yaitu pisau, lalu bulu adalah rambut halus yang merupakan benda mati, semenara kata memasukkannya diibaratkan benda runcing yang di masukkan ke sesuatu tempat yang sempit. Jadi teka-teki di atas dipersamakan ke dalam persamaan dengan benda.

Masuak tagang, kalua kandua, apo koyo? Urang manggiliang tabu

Masuk tegang, keluar kendor apa itu? orang menggiling tebu

Pada pertanyaan di atas, kata tagang (tegang) dan kandua (kendor) merupakansifat benda mati, contohnya tiang yang lurus akan dalam keadaan tegang, sementara apabila sebuah tali diikatkan pada tiang dalam keadaan tidak erat, maka tali tersebut akan kendor. Jadi teka-teki di atas dipersamakan ke dalam persamaan dengan benda.

Bom jatuah, bendera tagak, apo koyo? Jawih tacirik

Bom jatuh, bendera tegak, apa itu? sapi sedang buang air besar

Pada pertanyaan di atas, kata bom dan bendera merupakan jenis benda mati, bom biasanya digunakan dalam keadaan darurat untuk membasmi sesuatu, sedangkan bendera merupakan benda mati yang berbahan benang dan dikibarka.

Urang gaek babaju basi, a tu? lokan

Orang tua berbaju besi, apa itu? tiram

Pada pertanyaan di atas, kata babaju basi (berbaju besi) merupakan benda mati berbahan besi yang di olah bentuk pakaian. Biasanya baju besi ini dipakai pada zaman kerajaan. Jadi teka-teki di atas dipersamakan ke dalam persamaan dengan benda.

Anaknyo dipijak-pijak, induaknyo di uruik-uruik, a tu? janjang

Anaknya diinjak-injak, ibunya diurut-urut, apa itu? tangga

Pada pertanyaaan di atas, kata dipijak-pijak (diinjak-injak) dan diuruik-uruik (diurut-urut) menggambarkan sebuah benda mati yang terletak dibawah untuk di injak-injak seperti lantai, tangga, tanah dan alas lainnya, sementara yang di urut- urut maksudnya benda yang biasa di pegang untuk bertumpu seperti penyangga pada tangga, tiang peyembarangan, pembatas jalan, apapun benda yang berfungsi untuk disentuh. Jadi teka-teki di atas dipersamakan ke dalam persamaan dengan benda.

Dipiciak puseknyo, tabulalang matonyo, a tu? senter

Dicubit pusarnya, melotot matanya, apa itu? senter

Pada pertanyaan di atas, kata "dicubit pusarnya, melotot matanya" merupakan sifat benda yang bisa disentuh, seperti kata dipiciak (dicubit) suatu benda dan tabulalang matonyo (melotot matanya) dari benda yang disentuh.

Kalau paguno dicampakkan, kalau ndak paguno basimpan, a tu? Jalo

Kalau perlu dibuang, kalau tidak perlu disimpan, apa itu? jala

Pada pertanyaan di atas, kata dicampakkan (dibuang) dan basimpan (disimpan) merupakan sifat benda mati, berkaitan dengan jawaban dari pertanyaan ini yaitu jalo (jala). Jala merupakan benda mati yang digunakan untuk alat 
menangkap ikan. Cara kerjanya ketika digunakan jala akan ditebar, lalu ditarik kembali ketika ikan sudah masuk perangkap jaring jala. Jadi teka-teki di atas dipersamakan ke dalam persamaan dengan benda.

Sakali aia gadang, kasadonyo dianyuikkannyo, batu gadang kama baranjaknyo? Ka ateh

Sekali air besar, semuanya hanyut, batu besar kemana beranjaknya? Ke atas

Pada pertanyaan di atas, kata air dan batu merupakan benda mati yang saling berdekatan. Air sangat bermanfaat bagi kebutuhan sehari-hari makhluk hidup. Jadi teka-teki di atas dipersamakan ke dalam persamaan dengan benda

Batalantak oto ijau jo oto merah, nan masuak jurang oto putiah, apo tu? Ubek rangik

Tabrakan mobil hijau dengan mobil merah, yang masuk jurang mobil putih, apa itu? obat nyamuk

Pada pertanyaan di atas, kata oto (mobil) merupakan benda mati dan alat transportasi yang dikendalikan oleh makhluk hidup berfungsi untuk membawa benda mati maupun hidup. Jadi teka-teki di atas dipersamakan ke dalam persamaan dengan benda.

Di atehnyo api, di bawahnyo aia, apo ko yo? Minyak tanah

Diatasnya api, dibawahnya air, apa itu? minyak tanah

Pada pertanyaan di atas, api dan air merupakan benda mati yang mempunyai sifat aktif, seperi api yang bisa membakar apa saja yang ada didekatnya, sedangkan air bisa membuat basah apa saja yang ada disekitarnya. Jadi teka-teki diatas dipersamakan ke dalam persamaan dengan benda.

Ciek kuburan banyak maiknyo, a tu? Korek api

Satu kuburan, banyak manyatnya, apa itu? korek api

Pada pertanyaan di atas, kata kuburan merupakan benda mati, atau tempat terakhir mayat disemayamkan. Jadi teka-teki di atas dipersamakan ke dalam persamaan dengan benda.

Rumah gadang pagaruyuang, sabalik pintu jo tingkoknyo, tapi ciek nan paguno, a tu? Anak kunci Rumah gadang pagaruyung, sekeliling pintu dan jendelanya, tapi satu yang berguna, apa itu? anak kunci

Pada pertanyaan di atas, kata Rumah Gadang, pintu, tingkok (jendela) merupakan benda mati yang ada pada sebuah rumah, setiap rumah pasti memiliki pintu, jendela serta kuncinya. Semua itu digolongkan ke dalam benda mati. Jadi teka-teki di atas dipersamakan ke dalam persamaan dengan benda.

Cabuik lubang, tingga tiang, co takok? cincin

Cabut lubang, tinggal tiang, coba tebak? cincin di tangan

Pada pertanyaan di atas, kata lubang dan tiang merupakan benda mati yang bisa dijumpai dipinggir jalan. Jadi teka-teki di atas dipersamakan ke dalam persamaan dengan benda.

Jatuah ka bawah, dicari ka ateh, apo tu? tirih

Jatuh kebawah, dicari ke atas, apa itu? atap bocor

Pada pertanyaan di atas, jatuh kebawah, dicari ke atas merupakan kalimat yang menunjukkan sebuah benda mati yang jatuh, bahkan kata dicari lebih memperjelas kalau yang dmaksud adalah sebuah benda. Jadi teka-teki di atasdipersamakan ke dalam persamaan dengan benda.

Basisiak bukannyo nago, bagonjong bukannyo rumah, bapayuang bukannyo rajo, co takok? naneh 
Bersisik bukannyo naga, bergonjong bukannya rumah, berpayung bukannya raja, coba tebak? buah nanas

Pada pertanyaan di atas, kata nago (naga) merupakan persamaan dengan binatang, sedangkan rumah merupakan persamaan dengan benda, dan rajo (raja) merupakan persamaan dengan manusia, namun jawabannya adalah naneh (nanas) persamaan dengan tanaman. Jadi teka-teki di atas bisa dipersamakan kedalam empat jenis tersebut berdasarkan sifatnya masing-masing. (sama dengan 3.3.2)

Ado kandang indak bapintu, banyak cik kambiang didalamnyo, apo tu? batiak

Ada kandang tidak berpintu, banyak kotoran kambing didalamnya, apa itu? Pepaya

Pada pertanyaan di atas, "ada kandang tidak berpintu, banyak kotoran kambing didalamnya" merupakan kalimat yang menunjukkan benda mati yaitukandang. Kandang merupakan tempat tinggal hewan ternak yaitu kambing yangdipenuhi kotorannya. Jadi teka-teki ini dipersamakan ke dalam persamaan dengan benda.

Masuak karuang lai, masuak ituangan indak, a tu? Antimun bungkuak

Masuk karung iya, masuk hitungan tidak, apa itu? mentimun bungkuk

Pada pertanyaan di atas, kalimat "masuk karung iya, masuk hitungan tidak” merupakan kalimat yang merujuk ke sebuah benda mati yang dimasukkan ke dalam karung. Jadi teka-teki di atas dipersamakan ke dalam persamaan dengan benda.

Kok di caliak rancak ruponyo, lah takubak busuak didalam, a tu? Ambacangbatamiluak

Kalau di lihat elok rupanya, sudah dibuka busuk didalam, apa itu? ambacang berulat

Pada pertanyaan di atas, "kalau dilihat elok rupanya, sudah dibuka busuk didalam" merupakan kalimat yang menunjukkan sebuah benda yang bisa disentuh dan dilihat dengan mata. Jadi teka-teki di atas dipersamakan ke dalam persamaan dengan benda.

Sarumpun samo disabik, lah ditampi mangko tasisiah, a tu? Atah bareh

Serumpun sama disabit, sudah ditempi maka tersisih, apa itu? atah beras

Pada pertanyaan di atas, kata disabik (disabit) dan ditampi (ditempi) merupakan kata kerja yang menggunakan benda. Sabit adalah benda tajam yang digunakan untuk memotong, sedangkan tampi adalah benda yang digunakan untukmenampis atau menyisihkan beras dengan atah. Jadi teka-teki di atas dipersamakan ke dalam persamaan dengan benda.

Ambiak duri bapaga duri, didalam sarugo, dilua narako, co takok? durian

Ambil duri dipagar duri, didalam surga, diluar neraka, coba tebak? Durian

Pada pertanyaan di atas, kata "duri" merupakan benda asing yang bisa melukai seseorang apabila tersentuh. Duri yang dimaksud adalah duri buah-buahan yang mempunyai rasa yang nikmat dan aroma yang menyengat yaitu durian. Jaditeka-teki di atas dipersamakan ke dalam persamaan dengan benda.

Babiliak lai, bapintu indak, apo tu? buluah

Berkamar iya, berpintu tidak, apa itu? bambu 
Pada pertanyaan di atas, kata babiliak (berbilik) dan bapintu (berpintu) merupakan benda mati yang ada didalam sebuah rumah, babibiliak artinya adalah sebuah kamar dalam sebuah rumah, sedangkan bapintu maksudnya mempunyai pintu. Jadi teka-teki di atas dipersamakan ke dalam persamaan dengan benda.

Pariuak masak, nasi badatuih, aya tu? piraweh

Panci matang, nasi masih mentah, apa itu? jambu biji

Pada pertanyaan di atas, kata paruiak (panci) dan nasi merupakan benda mati. Panci digunakan untuk memasak, dan nasi adalah benda mati untuk dikonsumsi. Jadi teka-teki di atas dipersamakan ke dalam persamaan dengan benda.

Kaciak basanggua, gadang bagerai, a tu? paku

Kecil bersanggul, besar digerai, apa itu? pakis

Pada pertanyaaan di atas, kata basanggua (bersanggul) dan bagerai (digerai) adalah rambut, rambut merupakan benda mati yang dapat tumbuh disetiap mahkluk hidup. Arti dari basanggua (bersanggul) adalah bentuk rambut yangdigulung atau dibentuk supaya rapi, sedangkan digerai merupakan keadaan rambutyang dibiarkan terurai ke bawah begitu saja. Jadi teka-teki di atas dipersamakan kedalam persamaan dengan benda.

Taro kaciak babaju hijau, Lah gadang babaju sirah, a tu? lado

Ketika kecil berbaju hijau, sudah besar berbaju merah, apa itu? cabe

Pada pertanyaan di atas, kata babaju hijau (berbaju hijau) dan babaju sirah (berbaju merah) merupakan pakaian yang dikenakan seseorang berwarna hijau danberwarna merah. Jadi teka-teki di atas dipersamakan ke dalam persamaan dengan benda.

Kateh-kateh basuo Urang babaju maniak, a tu? Cubadak

$\mathrm{Ke}$ atas- ke atas bertemu orang berpakaian manik, apa itu? nangka tergantung

Pada pertanyaan di atas, kata babaju maniak (berbaju manik) merupakanpakaian yang memiliki motif manikmanik timbul dipermukaan baju. Jadi teka- teki di atas dipersamakan ke dalam persamaan dengan benda.

Barampek manumbuak, baduo manampi, surang mahalau, aya tu? kabau

Berempat menumbuk, berdua menampi, satu menghalau, apa itu? kerbau

Pada pertanyaan di atas, kata manumbuak (menumbuk), manampi (menampi) dan mahalau (menghalau) merupakan kata kerja yang dilakukan oleh mahkluk hidup, dengan menggunakan benda sebagai medianya, misalnya, menumbuk dengan benda tumbul agar makanan bisa halus, sementara menampi adalah alat untuk membersihkan beras, lalu menghalau menggunakan benda panjang sebagai alat penghalaunya. Jadi teka-teki di atas dipersamakan ke dalam persamaan dengan benda.

\section{PENUTUP}

Setelah melakukan penelitian dapat disimpulkan bahwasannya penelitian inibertujuan untuk mendokumentasikan serta mengklasifikasikan jenis dan kategori teka-teki Minangkabau di Kabupaten Agam. Dari 16 Kecamatan yang ada di Kabupaten Agam, peneliti mendapatkan masing-masing 5 data disetiap Kecamatan dengan satu informan, berikut data wilayahnya yaitu:1) Tanjung Mutiara; 2) Lubuk Basung; 3) Ampek Nagari; 4) Tanjung

Jurnal Elektronik WACANA ETNIK - Vol 8 No 2, 2019, (166 - 181) p ISSN 2089-8746, e ISSN 2302-7142 
Raya; 5) Matur; 6) IV Koto; 7) Malalak; 8) Banuhampu; 9) Sungai Pua; 10) Ampek Angkek; 11) Candung; 12) Baso; 13) Tilatang Kamang; 14) Kamang Magek; 15) Palembayan; 16) Palupuh.

Dari delapan puluh data tersebut diklasifikasikan berdasarkan sifat ada tujuh kategori umum yaitu: 1) persamaan dengan mahkluk hidup, terdapat tiga belas data 2) persamaan dengan binatang,terdapat enam belas data, ditambah satu data yang dipersamakan ke dalam persamaan dengan manusia, 3) persamaan dengan manusia, terdapat delapan belas data,ditambah satu data yang dipersamakan ke dalam persamaan dengan binatang 4) persamaan dengan tanaman, terdapat empat data dan 5) persamaaan dengan benda, terdapat tiga puluh satu data.

Penelitian ini masih jauh dari kesempurnaan, namun meskipun demikian peneliti sangat berharap bagi generasi muda agar menjaga budaya kita sendiri, agar teka-teki minang ini tetap dapat diketahui oleh generesi selanjutnya. Peneliti sangat antusias dalam upaya pengarsipam agar data yang dikumpulkan bisa diwariskandalam bentuk tertulis, kerena dikhawatirkan proses pewarisan tidak berjalan lancar, teka-teki ini akan punah begitu saja sebab terbatasnya informan.

\section{REFERENSI}

Armayunita, Yeni, dkk . 2017. "Teka-Teki Masyarakat di Nagari III Koto Aur Malintang Timur Kecamatan IV Koto Aur Malintang Kabupaten Padang Pariaman”. (jurnal). Padang: Universitas Negeri Padang.

Bascom, William R. 1954. Verbal Art. The Journal of American Folklore"Vol. 68 No. 269, pp. 245-252.

Bogdan, Robert dan Taylor. 1992. Pengantar Metode Penelitian Kualitatif Terjemahan oleh Arief Rurchan, Surabaya: Usaha Nasional,.

Brunvand, Jan Harold. 1978. The Study of American Folklore an Introduction. NewYork. W.W. Norton and CoInc.

Danandjaja, James. 1984. Folklor Indonesia:ilmu gosip, dongeng dan lain-lain. Jakarta: Grafiti Pers.

Dundes, Alan. 1966. "The American Concept of Folklore. Journal of the Folklore Institude. Vol.3, No.3, [ Special issue: The Yugoslav-American Folklor Seminar (Dec),pp.226-249.

Navis, A.A. 1984. Alam Takambang Jadi Guru: Adat dan Kebudayaan Minangkabau. Jakarta: Grafiti Press.

Oktafrian, Hasanuddin, dkk. 2018."Pertanyaan Tradisional Masyarakat di KenagarianSungai Pinang Kecamatan Koto XI Tarusan Kabupaten Pesisir Selatan”.(jurnal). Padang: Universitas Negeri Padang.

Purwanto, Andi (2010) "Analisis isi dalam fungsi Cerita Prosa Rakyat di Kenagarian Koto Besar Kabupaten Dharmasraya". Padang: Universitas Andalas

Website Resmi Kabupaten Agam "Buku Data Perspektif Gender Kabupaten Agam Tahun 2018. (httpps://agamkab.go.id)

Yuberko Arlin Riri. 2014. "Mitos Larangan di Kanagarian Puluik-Puluik Selatan Kecamatan Bayang Utara Kabupaten Pesisir Selatan". Padang:Universitas Andalas 